\title{
Contaminação invisível: Uso de agrotóxicos e descarte de embalagens na microrregião de Miguel Pereira e Paty do Alferes
}

\author{
Invisible contamination: Use of pesticides and disposal of packages in the Miguel Pereira and Paty \\ do Alferes micro-region \\ Contaminación invisible: Uso de plaguicidas y eliminación de envases em la microregión de Miguel \\ Pereira y Paty do Alferes
}

Recebido: 14/04/2021 | Revisado: 20/04/2021 | Aceito: 22/04/2021 | Publicado: 08/05/2021

\author{
Lorye de Araujo Melo \\ ORCID: https://orcid.org/0000-0003-0846-5876 \\ Universidade Federal Rural do Rio de Janeiro, Brasil \\ E-mail: loryemelo@gmail.com \\ Fabiola de Sampaio Rodrigues Grazinoli Garrido \\ ORCID: https://orcid.org/0000-0001-5177-1241 \\ Universidade Federal Rural do Rio de Janeiro, Brasil \\ E-mail: fabiola_srg@yahoo.com.br
}

\begin{abstract}
Resumo
O pequeno produtor está presente no contexto da produção agrícola que sustenta o Brasil, e sofre os primeiros impactos dessas substâncias sintéticas empregadas na manutenção da lavoura, o que foi motivação para propor o presente estudo. O objetivo geral deste estudo foi examinar o uso de pesticidas nos municípios de Miguel Pereira e Paty do Alferes, bem como avaliar o descarte de embalagens através da análise feita com grupos focais. A partir do estudo, percebeu-se correlação entre escolaridade do produtor e manuseio correto e menos deletério de pesticidas. Alguns produtores expuseram a necessidade de diversificação de culturas para sobrevivência de suas propriedades, tendo em vista a impossibilidade de aquisição de doses crescentes de agrotóxicos para a cultura do tomate. No entanto, sem a devida orientação técnica, não perceberam a possibilidade de contaminação do aquífero pelo uso de agrotóxicos, estão sujeitos às doenças do sistema nervoso central e podem bioacumular contaminantes.
\end{abstract}

Palavras-chave: Olerícolas; Ecotoxicologia; Pesticidas; Saúde.

\begin{abstract}
The small producer is present in the context of agricultural production that sustains Brazil, and suffers the first impacts of these synthetic substances used in the maintenance of crops, which was the motivation to propose the present study. The general objective of this study was to examine the use of pesticides in the municipalities of Miguel Pereira and Paty do Alferes, as well as to evaluate the disposal of packaging through analysis carried out with focus groups. From the study, it was noticed a correlation between producer education and correct handling and less harmful pesticides. Some producers exposed the need for diversification of crops for the survival of their properties, in view of the impossibility of acquiring increasing doses of pesticides for the cultivation of tomatoes. However, without proper technical guidance, they did not realize the possibility of contamination of the aquifer by the use of pesticides, are subject to diseases of the central nervous system and can bioaccumulate contaminants.
\end{abstract}

Keywords: Vegetables; Ecotoxicology; Pesticides; Health.

\section{Resumen}

El pequeño productor está presente en el contexto de la producción agrícola que sustenta Brasil, y sufre los primeros impactos de estas sustancias sintéticas utilizadas en el mantenimiento de los cultivos, lo que fue el motivo para proponer el presente estudio. El objetivo general de este estudio fue examinar el uso de plaguicidas en los municipios de Miguel Pereira y Paty do Alferes, así como evaluar la disposición de envases a través de análisis realizados con grupos focales. A partir del estudio, se observó una correlación entre la educación del productor y el manejo correcto y pesticidas menos dañinos. Algunos productores expusieron la necesidad de diversificación de cultivos para la supervivencia de sus propiedades, ante la imposibilidad de adquirir dosis crecientes de plaguicidas para el cultivo de tomate. Sin embargo, sin la debida orientación técnica, no se dieron cuenta de la posibilidad de contaminación del acuífero por el uso de pesticidas, están sujetos a enfermedades del sistema nervioso central y pueden bioacumular contaminantes.

Palabras clave: Hortalizas; Ecotoxicología; Pesticidas; Salud. 


\section{Introdução}

Ao se considerar o conceito de saúde em sua amplitude, na perspectiva biopsicossocial, as comorbidades que permanecem após a exposição dos humanos aos agrotóxicos são infalíveis no comprometimento das relações entre os homens e o ambiente contaminado. Áreas não agriculturáveis, águas contaminadas, impactos sobre o sistema de saúde e a previdência social são exemplos de uma sucessão de efeitos deletérios a partir da exposição intermitente ou continuada aos pesticidas. O modelo biopsicossocial de saúde implica ouvir e conhecer a prática para identificar pontos que possam ser corrigidos ou possam ser melhor orientados por um suporte profissional (Marco, 2006). Ainda assim, aprofundamentos na abordagem holística de saúde trazem à tona não apenas a ausência de enfermidades, mas o relacionamento entre o homem e seu entorno (Juarez, 2011). Principalmente considera-se nesse contexto de saúde as relações entre os humanos e o ambiente, a conservação dos recursos e a interação entre os componentes desse ambiente e a vida humana.

Desde 2008 o Brasil se destaca como o maior consumidor de agrotóxicos do mundo. Divulgado pelo Ministério da Saúde em 2016, o Relatório Nacional de Vigilância em Saúde de Populações Expostas a Agrotóxicos indica que houve um aumento de 13\% das vendas de agrotóxicos no País, com faturamento líquido de R\$25 bilhões (Ministério da Saúde, 2016).

Os riscos à saúde humana sobrevêm tanto para aqueles que manipulam diretamente os agrotóxicos como para aqueles que são afetados indiretamente trabalhando nas plantações, consumindo água e alimentos que apresentem resíduos de agrotóxicos. Os principais efeitos sobre a saúde humana relatados na literatura compreendem: alergias; distúrbios gastrintestinais, respiratórios, endócrinos, reprodutivos e neurológicos; neoplasias; mortes acidentais; suicídios; entre outros (World Health Organization, 2010).

Especialmente certas culturas guardam uma estreita relação com a aplicação de substâncias sintéticas que bioacumulam, ou seja, aumentam sua concentração nos tecidos de plantas e animais. O cultivo de pimentão, tomate, ou o morango não foge do crescimento de fungos e bactérias e o aumento das populações de insetos. Isso exige o controle para que não haja comprometimento das lavouras. No contexto da agricultura familiar, responsável pela produção da maior parte de alimentos consumidos no país, o recurso está no uso de pesticidas para o controle de pragas. Contudo, carecem de amparo quanto à aquisição e formulação de pesticidas e destinação de resíduos da agricultura.

A perspectiva desse trabalho residiu na análise da rotina de destinação de resíduos em propriedades escolhidas ao acaso em ambas as cidades. São propriedades que podem refletir a realidade de outras famílias e produtores em cidades distribuídas pelo estado do Rio de Janeiro.

Além dos efeitos conhecidos, a sinergia entre as substâncias e a interação com os recursos naturais são potencialmente fatores que dificultam o monitoramento dessas substâncias em cadeias tróficas. Desde o século XX, a preocupação das nações em torno de substâncias sintéticas tem apresentado desdobramentos legais que endureceram a regulação da síntese, produção e liberação na Europa, EUA, Canadá e Ásia (Leopold, Roberts \& Matthiessen, 2017). Nesses países, desde a década de 1970, o desenvolvimento de substâncias, desde fármacos até agrotóxicos, foi restrito por legislação e fiscalização rígidas. Em contrapartida, a liberação de substâncias sintéticas em países em desenvolvimento foi incentivada (Bernhardt et al., 2017). A revisão de Bernhardt et al. (2017) fez uma análise sobre a mudança climática global e destaca o uso de fertilizantes nitrogenados, bem como correlaciona mudanças significativas de parâmetros climáticos à produção de novas moléculas sintéticas aplicadas à indústria farmacêutica e à produção agrícola.

O Sistema Nacional de Informações Tóxico-farmacológicas (SINITOX), plataforma da Fundação Oswaldo Cruz, destaca a queda na participação dos Centros de Informação e Assistência Toxicológica (CIATs) no Brasil. Isso poderia esconder um aumento nos casos de intoxicação. No entanto, a análise feita por CIAT garante que aumentou. Dessa forma, os casos de intoxicações e envenenamentos não decresceram no país, que mantém um número crescente de autorizações para uso de substâncias e produtos banidos da União Europeia e de países em que a legislação reflete preocupação com os efeitos dessas 
substâncias na cadeia trófica (Gilson et al., 2020).

No Brasil, há mais incentivo ao uso de agrotóxicos no contexto econômico atual. Libera-se o uso das substâncias apenas pela avaliação realizada pelas empresas que registram os produtos agrotóxicos. O Ministério da Agricultura aprovou em 2020 substâncias altamente perigosas (16 substâncias) e 235 muito perigosas. Em 2021, já somam 67 registros, após o recorde de 493 em 2020 (Oliveira \& Tooge, 2021, Gilson et al., 2020). Pelo menos dois agrotóxicos aprovados agora estão proibidos na União Europeia desde 2009. No entanto, ignoram-se os impactos das substâncias, doravante tratadas como pesticidas, sobre os recursos naturais. Brum et al. (2020) apontou como impacto significativo de pesticidas a exposição de organismos nãoalvos, especialmente aves insetívoras, cujo organismo é muito sensível à contaminação.

Especialmente entre os produtores familiares, a carência de apoio técnico para uso e destinação dos resíduos da lavoura é incipiente na agricultura convencional. Ao contrário das lavouras mecanizadas, no contexto da produção agrícola que sustenta o país, o homem está presente e sofre os primeiros impactos das substâncias sintéticas empregadas na manutenção da lavoura. Foi exatamente a primeira motivação para propor o presente estudo. Não se tratou apenas de um estudo quantitativo, mas pretendeu-se relacionar o comportamento de produtores das regiões de Paty do Alferes e de Miguel Pereira aos impactos na saúde com o uso de pesticidas. Originalmente, são regiões conhecidas pela produção de tomate, uma Solanaceae extremamente susceptível ao ataque de fungos, bactérias e insetos quando cultivada como monocultura.

Ao longo do estudo, foi possível correlacionar dados de propriedades com uso de agrotóxico, condição do produtor em relação às terras, nível de instrução da pessoa que dirige o estabelecimento, orientação técnica, uso de equipamentos de proteção e destinação das embalagens. Além disso, foi possível obter um panorama sobre a agricultura e o uso de pesticidas nas regiões objeto de estudo.

\section{Metodologia}

A pesquisa se fundamenta dentro do contexto definido pela aplicação de substâncias biocidas por produtores da agricultura de subsistência, portanto, delimitando-se um estudo de caso (Yin, 2015). A metodologia proposta foi qualitativa, direcionada para grupos focais dentro das propriedades, o que transitou através da observação participante (Gondim, 2003). A região é predominantemente produtora de olerícolas mantida com níveis de agrotóxicos acima da média (Souza et al., 2020). O desenvolvimento da pesquisa se apoiou em dois pontos: na abordagem sobre a saúde do trabalhador e sobre a percepção de contaminação por substâncias tóxicas e persistentes no ambiente. Na pesquisa, os grupos caracterizaram produtores familiares em dois municípios da região Centro Sul Fluminense.

A sequência metodológica empregada para a concepção da entrevista feita com os produtores rurais. A pesquisa considerou a análise da legislação sobre descarte, acondicionamento e disposição final dos resíduos da agricultura. Além disso, foram selecionadas duas regiões tradicionalmente agrícolas e determinados os grupos de Paty do Alferes e de Miguel Pereira.

\section{1. Área de Estudo}

A área de estudo está situada nos municípios de Paty do Alferes e Miguel Pereira, localizados na região Centro Sul Fluminense. O relevo é acidentado, com declividades variando entre $20 \%$ e $45 \%$ e, em alguns trechos, ultrapassando os $45 \%$, onde as terras apresentam um altíssimo grau de susceptibilidade à erosão. Em sua maioria devido às altas declividades, o relevo da região não permite a utilização de maquinário agrícola, portanto, o principal sistema de preparo do solo é a aração morro abaixo, sem a aplicação de práticas conservacionistas que visem o controle das perdas de solo e de água, maximizando a capacidade produtiva do solo e otimizando seu aproveitamento (Bertolino, 2004).

Apresenta um clima do tipo $\mathrm{Cw}$ (Köppen), com uma variação de $12{ }^{\circ} \mathrm{C}$ (junho a agosto) a $30^{\circ} \mathrm{C}$ (janeiro a março), sendo a região caracterizada por apresentar uma amplitude térmica média praticamente constante ao longo do ano. A 
precipitação pluviométrica varia de 1.100 a $1.700 \mathrm{~mm}$ anuais, sendo em média, os meses de janeiro e dezembro os mais chuvosos (em torno de $220 \mathrm{~mm}$ ) e julho e agosto, os mais secos (em torno de 19,8 mm) (Durigon, 2011). De acordo com a EMBRAPA Solos (2004) A microbacia é composta por Latossolos, nas áreas mais altas; Argissolos e Cambissolos, nas encostas de transição entre as maiores e as menores altitudes; e nas partes mais baixas há predomínio de Cambissolo, Argissolo e principalmente Gleissolo.

Segundo o último censo agropecuário do IBGE (2017) Miguel Pereira e Paty do Alferes possuem juntos 1.131 hectares utilizados para lavouras permanentes e 962 hectares destinados à lavouras temporárias. Enfatizando assim, a gigantesca produção agrícola da região. Há que se destacar que Miguel Pereira e Paty do Alferes, juntamente com os municípios de Volta Redonda, Piraí, Barra do Piraí, Paracambi, Mendes, Paraíba do Sul, Barra Mansa, Engenheiro Paulo de Frontin, Pinheiral, Rio das Flores, Valença e Vassouras constituem a região do Vale do Café (Figura 1).

Figura 1. Localização geográfica de Miguel Pereira e Paty do Alferes pertencentes a região do vale do café.

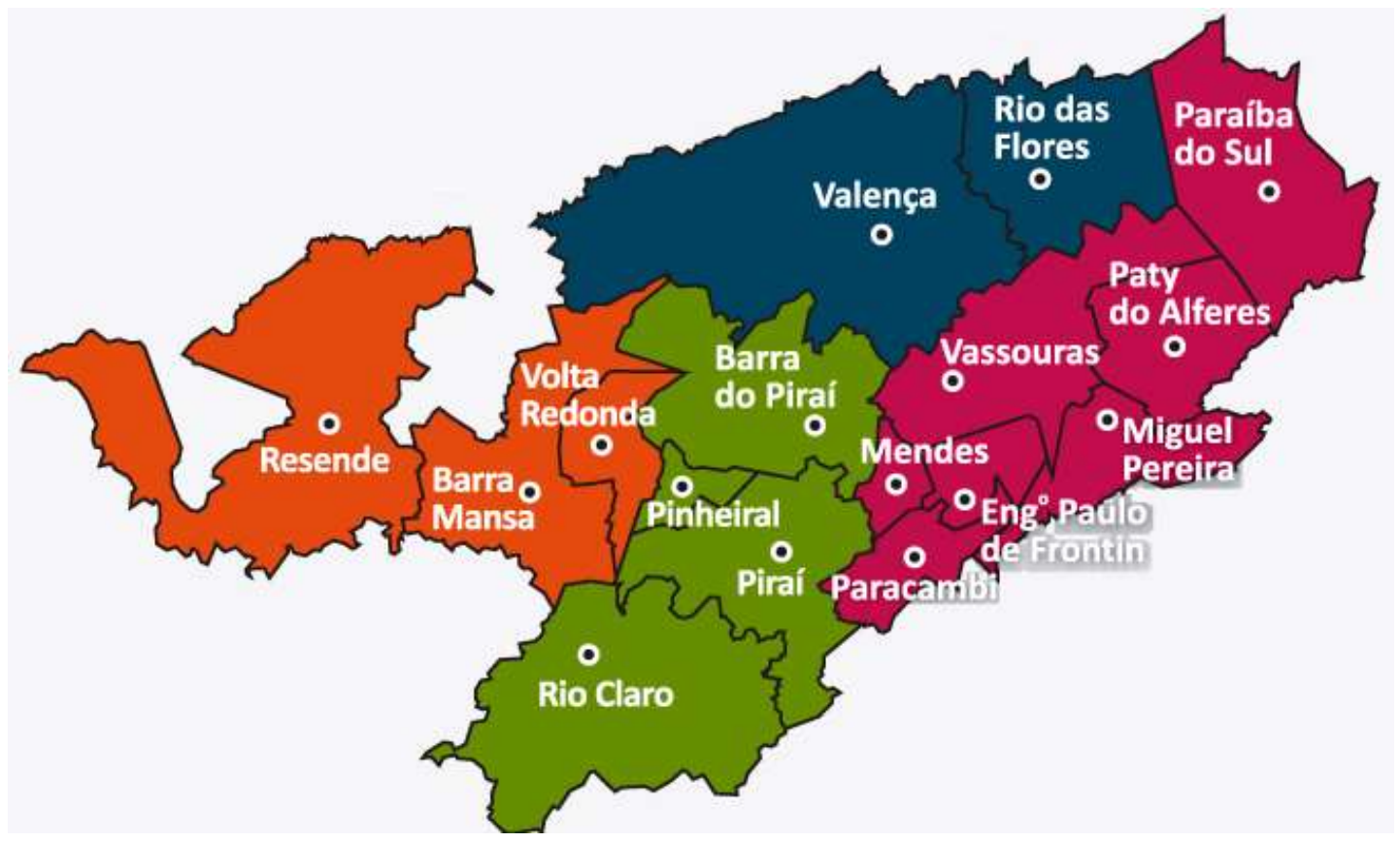

Fonte: Modificado de Instituto Cidade Viva (2013).

Esta vasta região histórica do interior fluminense utiliza o turismo como uma forma de diversificar a imagem de suas cidades, gerando novos pequenos investimentos e capacitação dos já existentes para poder atender demandas pontuais dos agentes que, com suas atrações, são os carros-chefes do turismo municipal (Cardoso; Cavalcanti, 2017)

\subsection{Acesso às áreas e entrevistas}

Estudos vêm sendo realizados na área desde a década de 90, mais especificamente em Paty do Alferes maior produtor de tomate do Estado do RJ e $3^{\circ}$ do Brasil (AEMERJ, 2017). O método de coleta de dados empregado no presente trabalho foi a entrevista de grupos focais.

Os métodos foram escolhidos visando riqueza e flexibilidade na coleta de dados a partir de uma abordagem direta e natural dos procedimentos da pesquisa qualitativa e que conduz os estudos em direção a uma aplicação holística, normalmente não disponíveis quando se aplica um instrumento individualmente ou utilizando uma técnica quantitativa (Oliveira, Leite Filho \& Rodrigues, 2007). 
As entrevistas com grupos focais são uma boa alternativa para explorar temas de pesquisa, coletando opiniões que podem auxiliar no entendimento de um dado fenômeno. Permite gerar ideias e hipóteses ou proposições, entender relações de causa e efeito, identificar elementos que compõem o tema em estudo ou identificar as bases de um sistema teórico. A pesquisa qualitativa proporciona um conhecimento mais profundo e subjetivo do cliente e, na prática, tem se tornado quase sinônimo de entrevista de grupo focal (Dias, 2000).

Geralmente os grupos focais são usados como um método único, mas em muitos casos eles são integrados em um modelo de múltiplos métodos com outros métodos qualitativos e, às vezes, com métodos quantitativos. Eles também são vistos como boas alternativas para a utilização apenas de entrevistas como base de dados da análise qualitativa. A vantagem é que eles não somente permitem análises de declarações e relatos sobre experiências e eventos, mas também do contexto interacional em que essas declarações e esses relatos são produzidos. Esse método acompanha demandas práticas e metodológicas especificas para a documentação e análise dos dados (Barbour, 2009).

Nesse contexto e visando objetividade e fidedignidade às informações adquiridas foi seguido um roteiro previamente elaborado e estruturado em formato de questionário com perguntas predeterminadas. A metodologia foi, portanto, padronizada.

A escolha dos grupos de agricultores foi realizada de forma casual, o único critério utilizado foi o fato de ser agricultor e trabalhar no município de Miguel Pereira e Paty do Alferes. O local das entrevistas foi em grande maioria nas próprias lavouras e quando os agricultores não estavam no seu local de trabalho. Foram indicados por vizinhos e transeuntes o local em que se encontravam e a coleta de informações realizada no respectivo local.

Os questionários foram organizados por temas: tipo de cultura; tipo de cultivo; fonte de abastecimento hídrico; condição do produtor em relação às terras (condição de posse sobre a propriedade); nível de instrução da pessoa que dirige o estabelecimento; uso de equipamento de proteção individual ou coletiva; transporte, armazenamento e descarte das embalagens de agrotóxicos; conhecimento sobre os efeitos dos agrotóxicos na saúde; sintomas e enfermidades ocasionadas à saúde e fiscalização da atividade.

Os entrevistados foram informados desde o início sobre o objetivo do estudo e sobre a não obrigatoriedade em responderem a todas as perguntas, uma vez que se tratava de pesquisa de opinião. $\mathrm{O}$ tempo das entrevistas foi diversificado, estimou-se entre 30 minutos e 1 hora. Foram visitados produtores em suas propriedades e respeitou-se a rotina de trabalho do respondente. A quantidade de entrevistados por grupo foi variável, visto que o número de agricultores se altera em cada área de plantio. Totalizaram-se 10 entrevistados, a saber 5 grupos focais em Miguel Pereira e 5 grupos focais em Paty do Alferes. As informações obtidas nas duas cidades foram contabilizadas e transformadas em gráficos únicos com os dados de ambos os municípios para melhor visualização dos resultados.

\section{Resultados e Discussão}

\subsection{Entrevistas com os Grupos Focais}

Os resultados das entrevistas com os grupos focais foram separados em tópicos e alguns dados obtidos foram correlacionados, a saber, os tipos de cultura e cultivo; escolaridade e uso de equipamentos de proteção individual, transporte e armazenamento e, por fim, as informações sobre o conhecimento dos efeitos dos agrotóxicos foram analisadas à luz dos sintomas de contaminação humana mais frequentemente relatados.

\subsubsection{Culturas e cultivo}

O principal tipo de cultura encontrada foi o de hortaliças em geral, seguidas por tomate, abóbora, maracujá, ponkan e milho, majoritariamente produzidas em cultivo convencional.

Embora Paty do Alferes seja tradicionalmente conhecida como a cidade do tomate, muitos agricultores relataram 
dificuldade em cultivá-los, visto que há necessidade de utilizar grande quantidade de agrotóxicos. O receituário do engenheiro agrônomo do CEASA (Centrais Estaduais de Abastecimento), principal comercio de pesticidas da região, limita a quantidade de substâncias.

O cultivo do tomate demanda aplicação intensa de pesticidas, principalmente no cultivo convencional (Carvalho et al., 2017). Frente à limitação para a obtenção dos agrotóxicos, os produtores foram uníssonos em relatar que passaram a comercializar outras culturas, conforme pode ser observado na Figura 2.

Figura 2. Tipos de Cultura e Cultivos encontrados em Miguel Pereira e Paty do Alferes-RJ.

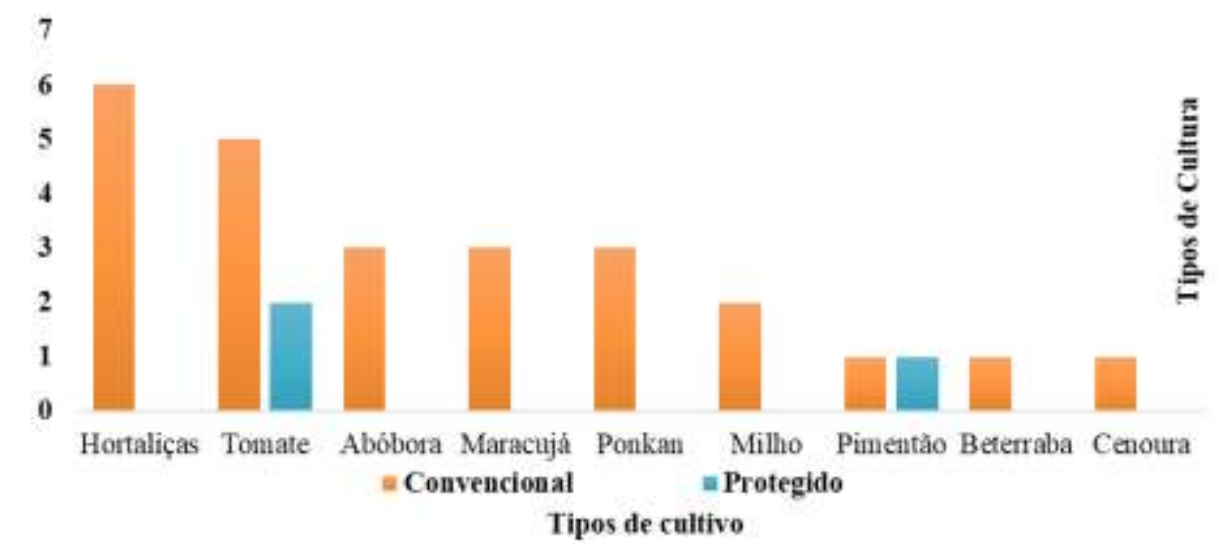

Fonte: Autores.

Pode-se observar que a prevalência entre as propriedades está no cultivo convencional, o que foi espelho do cultivo do tomate. Culturas protegidas deram-se no trato com tomate cereja, o que comercialmente apresentou viabilidade financeira, em função da boa aceitação comercial do produto.

Figura 3. Tomates cereja produzidos em cultivo protegido. O produtor ofereceu à autora os tomates colhidos para pronto consumo.

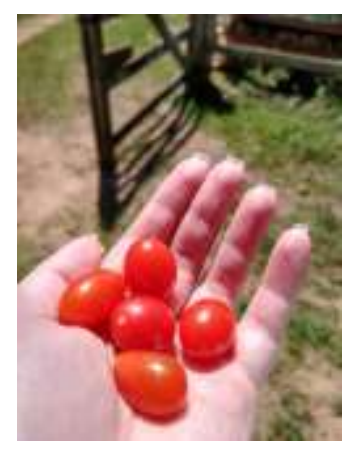

Foto: Lorye de Araujo Melo.

Ainda assim, o cultivo protegido é uma ferramenta efetiva para o aumento da produtividade em espécies oleráceas (Leonardo et al., 2008). As produções do pimentão e, em parte, do tomate podem ser mais controladas e isso facilita a fertirrigação. Importa observar que a limitação para obtenção de agrotóxicos influenciou diretamente o tipo de cultivo para que os agricultores da região pudessem manter seus negócios, uma parte deles migrou do cultivo tradicional para o cultivo protegido em estufas (Figura 3). 
Além da percepção dos agricultores sobre a demanda crescente de substâncias, a região do tomate tem perdido terras férteis para a erosão (Jardim, Fernandes \& Souza, 2017). Técnicas de cultivo convencional desprotegem o solo, submetem as partículas ao intemperismo hídrico com mais intensidade na ausência de cobertura vegetal. De certa forma, a diversificação de olerícolas, com abandono da monocultura, implica o uso do solo de uma forma menos impactante, com coberturas diferentes e menor emprego de pesticidas.

\subsubsection{Abastecimento de água}

É importante observar que a natureza química das substâncias aplicadas segue determinadas características que as tornam hidrossolúveis. Apresentam Kow (constante de partição etanol/água) abaixo de 1,0, ou seja, são facilmente solubilizadas e carreadas pela água. Por isso, foi interessante observar a fonte de abastecimento e irrigação, principalmente nessa região com tantas declividades e terrenos acidentados. A configuração da bacia pode apontar para o carreamento das águas de irrigação das culturas repletas de agrotóxicos.

Figura 4. Plantio em declividade atrás das moradias dos agricultores que utilizam água de poço para consumo. A aplicação dos pesticidas em declividade implica carreamento das substâncias, bem como interação entre elas frente à lixiviação.

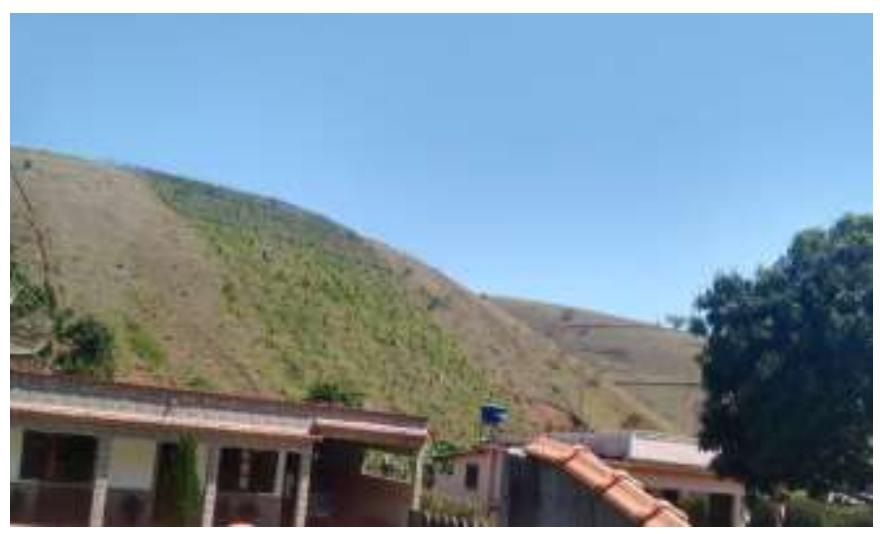

Foto: Lorye de Araújo Melo.

Em alguns casos, foi possível observar o plantio do tomate nas encostas e a água de abastecimento da família no sopé do morro (Figura 4). A partir dessa perspectiva, pode-se inferir o potencial contaminante da água tendo em vista dois fatores: o escoamento superficial e a percolação no perfil do solo. Em ambos os casos, a água de abastecimento não está isenta de dúvida sobre seu uso.

Na Figura 5 pode-se observar que as propriedades são abastecidas predominantemente por água de nascente e água de poço. Os agricultores relataram como um fato positivo, motivo de orgulho. Ainda assim, ao se observar o posicionamento da fonte de água, foi possível perceber as possibilidades de movimento por lixiviação ou escoamento superficial a partir dos pontos de aplicação dos agrotóxicos. A fonte de abastecimento da propriedade por vezes se encontrava em risco de contaminação. 
Figura 5. Abastecimento de água nas propriedades visitadas em Miguel Pereira e Paty do Alferes, com $18 \%$ de propriedades abastecidas com água de poço; $9 \%$ pela empresa de tratamento de água estatal (CEDAE) e $73 \%$ com consumo de água de nascente.

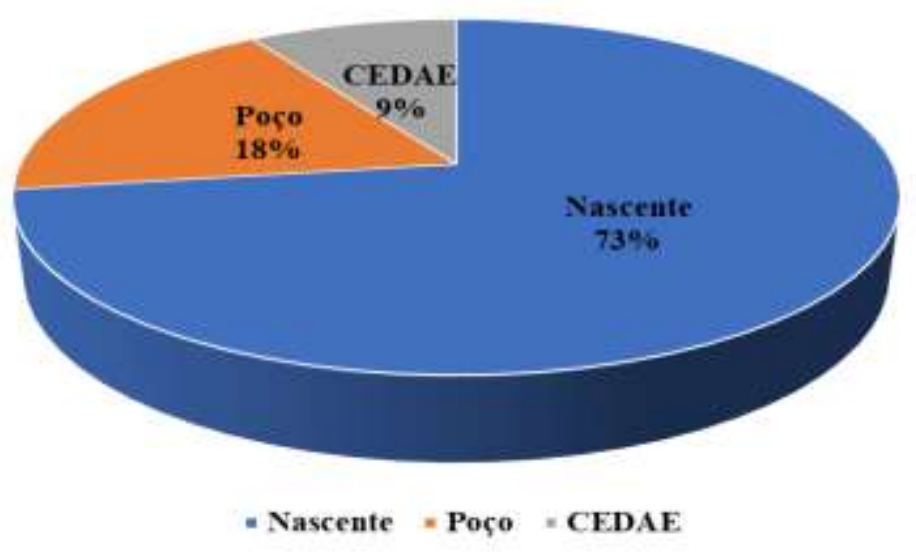

Fonte: Autores.

A Figura 5 traz a distribuição das fontes de água admitidas pelos produtores como próprias para uso na irrigação, na dessedentação da família e dos animais. Em sua maioria, os grupos apontaram pouca dependência de água tratada pela CEDAE (Companhia Estadual de Águas e Esgotos do Rio de Janeiro).

\subsubsection{Transporte de agrotóxicos}

O deslocamento de agrotóxicos é realizado majoritariamente pelos próprios agricultores em seus transportes particulares, sem qualquer prévia avaliação do potencial de periculosidade. Apenas uma propriedade faz uso do serviço de entrega oferecido pelo fornecedor (Figura 6).

Figura 6. Transporte de agrotóxicos das lojas até as propriedades dos agricultores entrevistados.

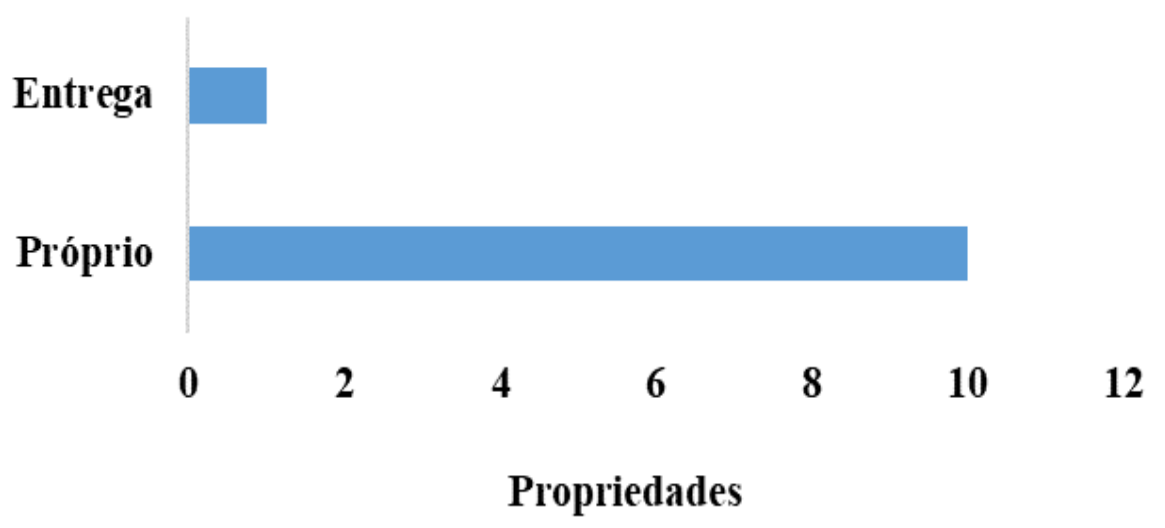

Fonte: Autores.

O transporte de produtos fitossanitários é uma tarefa de elevada responsabilidade e exige que sejam tomadas várias medidas de prevenção para diminuir os riscos de acidentes. Acerca do transporte e armazenamento de fitossanitários, é fundamental destacar o previsto no artigo 56 da Lei de Crimes Ambientais (9.605/98), que prevê pena de reclusão de um a quatro anos, adicionado de multa, em casos de o transporte e guarda serem realizados em discordância com a legislação, tudo isso combinado com o artigo 15 da Lei 7.802/89. 
Ainda que a orientação acerca da proteção ao trabalhador rural devesse decorrer de um apoio técnico qualificado, o produtor não pode se eximir das normas técnicas e legislação para manipulação de tais substâncias. Esse quadro ainda está posto na contramão de um movimento mundial a favor do emprego de técnicas e de um aparato sustentável e saudável no meio rural.

\subsubsection{Armazenamento de agrotóxicos}

O correto armazenamento bem como transporte adequado dos agrotóxicos é previsto por lei. Foi observado que $90 \%$ das propriedades possuíam um local específico para guardar os recipientes com agrotóxicos, o que era uma construção à parte da residência ou galpão próximos à plantação (Figura 7A). Apenas 10\% dos entrevistados armazenavam os pesticidas a céu aberto no meio da lavoura (Figura 7B).

Figura 7. Depósito para ferramentas e pesticidas utilizados no plantio (esquerda) e agrotóxicos diluídos em água e armazenados no centro da lavoura para irrigação contínua (direita).
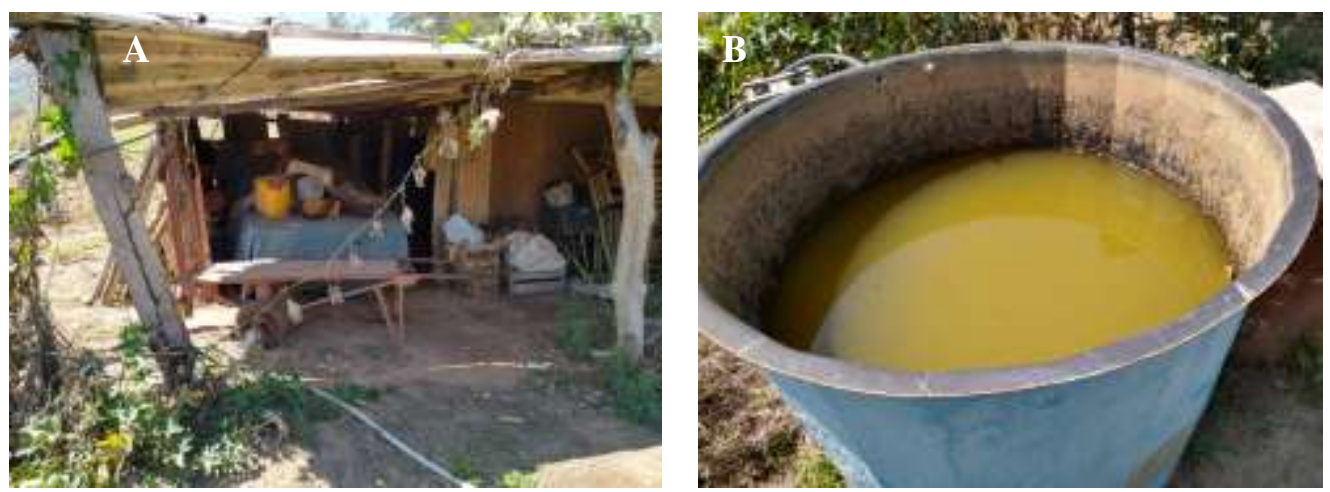

Foto: Lorye de Araújo Melo

De acordo com a Empresa Brasileira de Pesquisa Agropecuária (2010) Os agrotóxicos devem ser armazenados em local com boa ventilação, livre de inundações e distante de residências, instalações para animais ou de locais onde se armazenam alimentos ou rações. Os produtos devem ser devidamente agrupados em prateleiras, por classe de princípio ativo, nunca devem estar em contato direto com o piso e sempre apresentar os rótulos intactos. O depósito deve ficar trancado e sinalizado com uma placa indicativa alertando para a presença de material tóxico. Não é recomendável armazenar estoques de produtos além das quantidades para uso a curto prazo (no máximo um ciclo da cultura). Os restos de produtos devem sempre ser mantidos em suas embalagens originais.

\subsubsection{Descarte de embalagens}

Souza et al. (2020) haviam obtido relatos de armazenamento dos pesticidas de forma inadequada em pesquisa desenvolvida em Paty do Alferes e destacaram a demanda por assistência técnica como pressuposto para diminuir os riscos de exposição em ambiente laboral, e familiar. A questão em tela, quando analisada no âmbito de Paty do Alferes e Miguel Pereira, foi constatada no presente trabalho.

A Figura 8 retrata uma condição que apontaria para risco de contaminação do solo, dos corpos hídricos ou contaminação do homem diretamente. Ao serem questionados sobre a destinação das embalagens, os entrevistados relataram com mais frequência a devolução das embalagens aos postos de compra. Ainda assim, a queima e o simples descarte como mostra a Figura 11 foram apontados por alguns produtores. 
Figura 8. Destinação das embalagens e resíduos de agrotóxicos nas regiões entrevistadas.

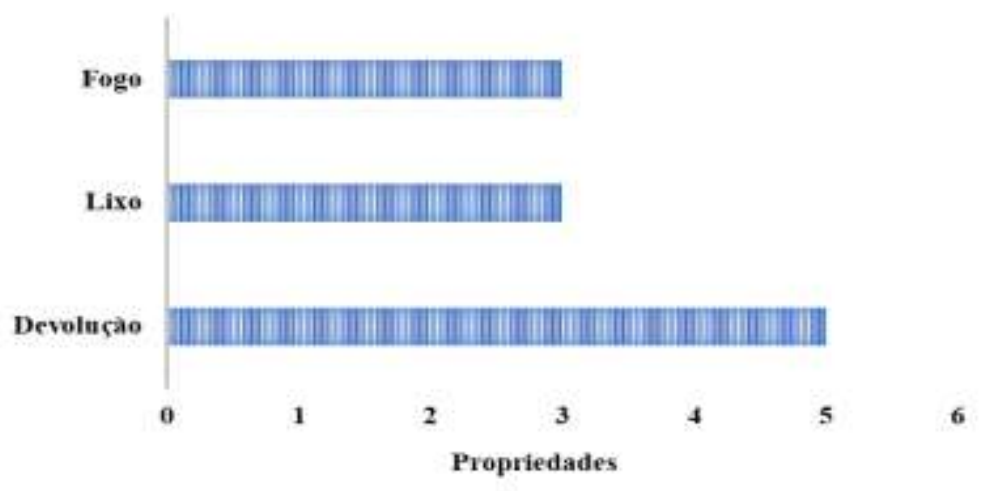

Fonte: Autores.

Houve casos em que os recipientes de pesticidas foram aproveitados para outras finalidades, tais como a colocação de embalagem vazia em um poste (Figura 9), simulando armadilha para captação de insetos. A manipulação é inevitável, bem como a funcionalidade atribuída aos recipientes, o que está em desacordo com a legislação que protege o produtor.

Figura 9. Embalagem de defensivo agrícola vazia utilizada em um poste situado em uma das propriedades visitadas.

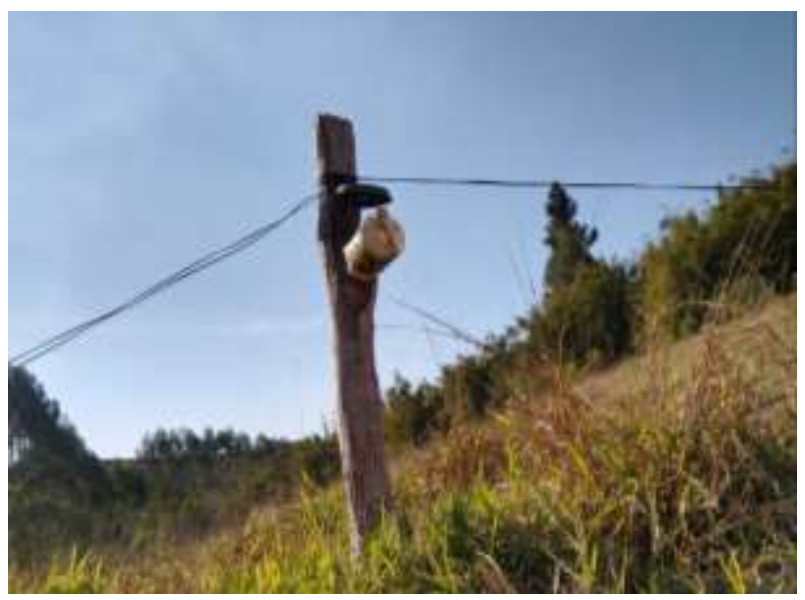

Foto: Lorye de Araújo Melo.

De acordo com a legislação em vigor, é obrigatório o recolhimento das embalagens vazias a uma unidade de recebimento autorizada pelos órgãos ambientais. Antes do recolhimento, é obrigatório que o agricultor efetue a tríplice lavagem (Lei 9.974/2000) inutilizando-os com furos nos tipos de embalagens que permitirem esta prática, enquanto as embalagens não laváveis devem permanecer intactas, adequadamente tampadas e sem vazamentos. As embalagens vazias devem ser acondicionadas em saco plástico padronizado que deve ser fornecido pelo revendedor. Dentro do prazo de até um ano (Lei 7.802/89) essas embalagens deverão ser entregues em um posto de recebimento cadastrado. O agricultor deverá receber um comprovante de entrega que deve ser guardado com a nota fiscal do produto. Caberá ao fabricante ou seu representante legal providenciar o recolhimento de todo o material depositado no posto de recebimento (Embrapa, 2010). O que cabe ser discutida é a forma como essa instrução é claramente transferida aos produtores, o contexto social e educacional com que recebe as normas e a ausência de assistência técnica. 


\subsubsection{Escolaridade e uso de equipamentos de proteção individual}

Ao se analisar a escolaridade dos agricultores e o uso de Equipamentos de Proteção Individual (EPI), ambos os parâmetros podem contribuir para a compreensão da forma como essas exigências são assumidas na prática dos proprietários. A Figura 10 retrata a correlação entre a escolaridade e o uso de EPI. Sousa et al. (2016) debruçaram-se sobre a percepção dos agricultores acerca do uso de EPI e concluíram que a maior parte dos agricultores está sujeita à contaminação. A aplicação de agrotóxicos faz parte da prática no cultivo convencional e a experiência atribui uma falsa imunidade aos efeitos das substâncias sobre a saúde.

Figura 10. Uso dos equipamentos de proteção individual correlacionado com os dados de escolaridade dos entrevistados em propriedades de Paty do Alferes e Miguel Pereira.

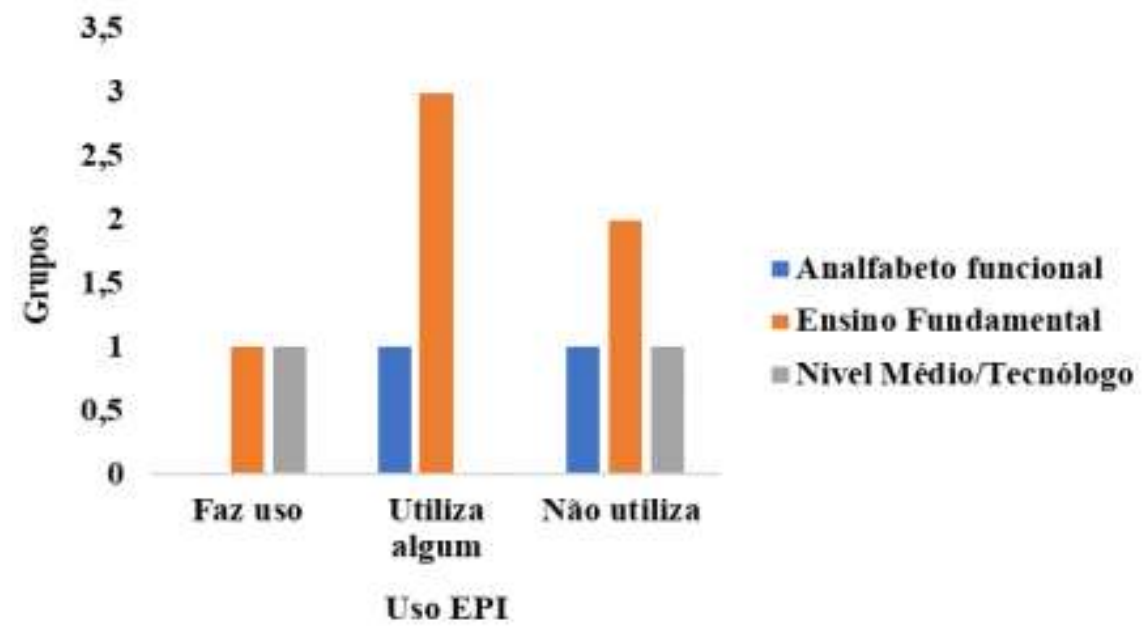

Fonte: Autores.

Não são consideradas informações no que diz respeito à bula e receituário agronômico, além de não armazenarem os agrotóxicos de forma correta, não usam equipamento de proteção individual, como observaram Souza et al. (2020). Isso corroborou os dados desta pesquisa. As pessoas com poucos anos de escolaridade, o que reflete os dados da média de escolaridade da população brasileira, declaram não fazer uso dos EPI, ou utilizam apenas algum deles. Ao se considerar as botas e chapéus, tratam-se dos únicos EPI que utilizam de forma geral.

Os produtores desconhecem os efeitos das substâncias sobre a saúde ao longo do tempo. Segundo Faria, Rosa e Facchini (2009) a escolaridade revelou efeito protetor contra a ocorrência de intoxicações na fase de alta exposição química. As pesquisas apontaram que mulheres eram contaminadas de forma crônica por lavarem as roupas dos cônjuges que trabalhavam na lavoura. Dessa forma, o simples conhecimento das normas para manipulação e armazenamento poderia evitar a exposição dos trabalhadores, seja de forma direta ou indireta.

Ainda que a baixa escolaridade seja um fator agravante para a contaminação, aguda ou crônica, cabe à gestão ambiental esgotar formas de reduzir as distâncias entre os produtores e as propostas agroecológicas para cultivo de olerícolas. Em muito isso deveria superar os riscos a que estão expostos esses trabalhadores rurais.

\subsubsection{Conhecimentos dos efeitos e sintomas na saúde}

A maior parte dos grupos de agricultores desconhece ou conhece pouco os efeitos dos agrotóxicos na saúde (Figura 11), contudo, durante as entrevistas foram relatados diversos sintomas de problemas de saúde que podem ser relacionados ao contato direto e indireto com pesticidas, como por exemplo, câncer e manchas na pele, distúrbios neurológios, tonteiras e 
desmaios.

Os pesticidas têm efeito biocida. Significa que a ação destes toxicantes não é restritiva, agindo indiscriminadamente em diferentes graus sobre toda forma de vida. Por isso, para muitos, o melhor termo seria biocida. Quanto à heterogeneidade química: mais de 600 princípios ativos registrados para uso biocida. Destes, cerca de 350 são utilizados em $98 \%$ dos agrotóxicos utilizados no Brasil (Moragas, 2003).

Entre as principais classes de substâncias, há organoclorados. O principal representante é o DDT. Quimicamente, são constituídos por carbono e cloro na forma de isômeros hexaclorociclohexano e ciclodienos. São cristalinos solúveis em solventes orgânicos. Organofosforados contêm um átomo central de fósforo pentavalente ao qual se ligam um oxigênio ou enxofre por dupla ligação. Há organofosforados derivados de flúor, altamente neurotóxicos, e clorofosforados. Carbamatos surgiram após 1950, juntamente com os organofosforados, a fim de abolir o uso dos organoclorados. Piretróides: são amplamente utilizados na proteção agrícola e doméstica, apresentam ação tóxica mais branda. Originalmente é inseticida natural extraído do crisântemo (Santos et al., 2007).

Dificilmente os trabalhadores são informados sobre os efeitos neurotóxicos dessas substâncias, mas relatam dores de cabeça, náuseas e tonteiras. Comportamentos agressivos, depressão e suicídios são frequentes entre as pessoas que tem contato com agrotóxicos. Algumas substâncias podem exibir efeito a longo prazo, com a exposição constante. Há substâncias sintéticas que bioacumulam no tecido adiposo e afetam as sinapses nervosas. Na entrevista houve relatos de sintomas relacionados à exposição aos biocidas. Ainda assim, não relacionaram completamente ao uso das substâncias e composições na lavoura, conforme apresentou-se na Figura 11.

Figura 11. Conhecimento dos efeitos na saúde e a presença de sintomas relatados pelos entrevistados.

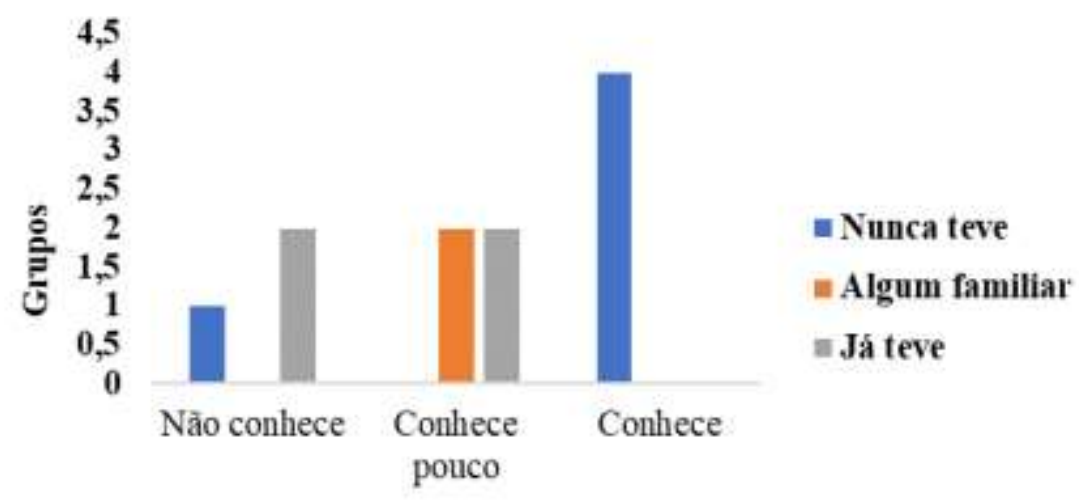

\section{Conhecimento dos efeitos na saúde}

Fonte: Autores.

Entre os respondentes, $70 \%$ afirmou que as propriedades nunca foram visitadas por fiscais, o que denota ausência de apoio técnico e demanda de um trabalho de modernização da agricultura que efetivamente é importante quando se trata de oferta de alimentos para maior parte dos lares da região. O caminho mais promissor do que a liberação de substâncias e composições que comprometem a saúde, seria oferecer aos pequenos produtores assistência técnica, caminhos para se pautar perspectivas mais interessantes no cultivo de alimentos.

\subsection{Aspectos legais}

A legislação brasileira que rege o uso de agrotóxicos é antiga, elaborada apenas um ano após a promulgação da Constituição da República de 1988. A Lei 7.802, de 11 de julho de 1989 (Lei dos Agrotóxicos), dispõe sobre os principais 
temas acerca do uso de agrotóxicos, desde a pesquisa, a experimentação, a produção, a embalagem e rotulagem, o transporte, o armazenamento, a comercialização, a propaganda comercial, a utilização, a importação, a exportação, o destino final dos resíduos e embalagens, o registro, a classificação, o controle, e até mesmo a inspeção e a fiscalização dos fitossanitários, seus componentes e afins.

Dentre as diversas disposições da lei supramencionada, destaque-se a definição dada para os agrotóxicos:

Art. $2^{\circ}$ Para os efeitos desta Lei, consideram-se:

I - Agrotóxicos e afins:

a) os produtos e os agentes de processos físicos, químicos ou biológicos, destinados ao uso nos setores de produção, no armazenamento e beneficiamento de produtos agrícolas, nas pastagens, na proteção de florestas, nativas ou implantadas, e de outros ecossistemas e também de ambientes urbanos, hídricos e industriais, cuja finalidade seja alterar a composição da flora ou da fauna, a fim de preservá-las da ação danosa de seres vivos considerados nocivos;

b) substâncias e produtos, empregados como desfolhantes, dessecantes, estimuladores e inibidores de crescimento;

Nesse mesmo diploma legal, dentre vários outros temas, há a instituição de obrigatoriedade do registro dos agrotóxicos para que os mesmos possam ser comercializados no país. Ressalte-se que o referido registro no órgão federal competente deve ser feito em consonância com as diretrizes e exigências dos órgãos responsáveis pelos setores de saúde, meio ambiente e agricultura.

O texto da Lei 7.802/89 não dava tratamento efetivo a diversas temáticas como às relativas à destinação de embalagens e o procedimento adequado para o descarte, de modo que proporcionava a maior probabilidade e possibilidade de contaminação ao meio ambiente. Tal lei segue vigente até a presente data. Entretanto, seu texto sofreu significativas modificações, trazidas pela Lei 9.974/2000, a fim de tentar reduzir as brechas legais. Dentre as alterações, pode-se registrar a obrigatoriedade da tríplice lavagem das embalagens de produtos com formulações miscíveis em água, bem como a maior preocupação com a destinação correta das embalagens desses produtos.

Além disso, pode-se citar a instituição da obrigatoriedade de devolução da embalagem de agrotóxico vazia, em até 1 (um) ano da compra, nos estabelecimentos comerciais em que foram adquiridos, na forma do artigo $6^{\circ}$, parágrafo $2^{\circ}$, do referido diploma. Tal prazo poderá ser estendido caso seja dada a devida autorização. Insta salientar que a fiscalização do cumprimento do prazo de devolução fora atribuída ao Poder Público, na forma do artigo $3^{\circ}$ da Lei em comento, que inseriu o artigo 12A (e incisos) na Lei 7.802/89.

Desta feita, há que se inferir que, com o implemento da Lei 9.974/2000 houve algum aumento na rigidez do controle de uso de pesticidas, bem como houve parametrização da destinação adequada dos invólucros de agrotóxicos, a fim de reduzir o impacto ambiental decorrente do uso destes.

Já em 2002, foi promulgado pelo então presidente Fernando Henrique Cardoso, o Decreto Lei 4.074/2002, que passou a regulamentar a lei 7.802/89, trazendo maior efetividade ao texto de 1989. Estabeleceu diretrizes, exigências e competências institucionais a serem observadas pelos órgãos federais responsáveis pelos setores da saúde, do meio ambiente e da agricultura, em uma tríade compartilhada para regulamentar o registro de agrotóxicos e, assim, classificar os agrotóxicos de acordo com o nível de periculosidade, conforme a Portaria IBAMA nº. 84/96 e autorizar (ou não) sua produção e comercialização.

Acerca das questões de periculosidade, há que se falar no uso de equipamentos de proteção individual e dos riscos ambientais inerentes à atividade agrícola, abordados na NR31. Dentre eles, pode-se destacar as diversas obrigatoriedades instituídas tanto para empregador, que é obrigado a supervisionar a atividade de seus empregados e a fornecer os EPI's, como para empregados, que podem sofrer sanções em caso de descumprimento às medidas de proteção adotadas pelo empregador.

Assim, em que pese a preocupação constante em tornar eficaz a redução dos riscos ambientais e para a saúde pública, há que se entender que, ainda assim, há contaminação por agrotóxicos. Esta, em que pese o ideal ser a sua inexistência, está 
regulada por um padrão mínimo aceitável. O Sistema Nacional de Vigilância Sanitária (SNVS) desenvolveu o PARA (Programa de Análise de Resíduos de Agrotóxicos em Alimentos) em 2001, a fim de estruturar um serviço para avaliar e promover a segurança dos alimentos em relação aos resíduos de agrotóxicos. Os resultados obtidos possibilitam traçar um diagnóstico da utilização de agrotóxicos nos alimentos de origem vegetal. Consequentemente, são fornecidos subsídios para a implementação de ações de natureza regulatória, fiscalizatória e educativa.

Deste modo, com o diagnóstico da utilização, fica facilitado o cálculo do IDA (Ingestão Diária Aceitável), que é um parâmetro de segurança definido como a quantidade máxima de agrotóxico que podemos ingerir por dia, durante toda a vida, de modo a não causar danos à saúde. A quantidade máxima de ingestão permitida é calculada para cada agrotóxico, e dela, depreende-se o LMR - Limite Máximo de Resíduos, que é a quantidade máxima de resíduos permitida em alimentos. Com base nesses parâmetros, é realizado o controle pelas agências fiscalizadoras e os agrotóxicos que não suprem essa base mínima, não recebem, via de regra, autorização para comercialização. Tudo isso na forma do art. $3^{\circ}$ da Lei 7.802/89.

Ademais, ainda sobre a Lei de Agrotóxicos, é importante destacar a série de obrigatoriedades regulamentadas: no artigo $7^{\circ}$ da lei supramencionada (Lei 7.802/89), há quesitos a serem cumpridos na embalagem do agrotóxico para comercialização, sendo necessárias diversas informações nos rótulos, como classificação toxicológica, instruções de uso e de perigos potenciais, de maneira que a compreensão seja facilitada.

Relativamente às responsabilidades civil, administrativa e penal pelos danos causados à saúde das pessoas e ao meio ambiente, o artigo 14 da Lei de Agrotóxicos trouxe um rol taxativo/exemplificativo, o qual fora atualizado pela Lei 9.974/2000, apontando os responsáveis nos casos em que não forem cumpridas as disposições na legislação vigente acerca do transporte, produção, comercialização e armazenamento de agrotóxicos.

Deste modo, fica evidente que a legislação pátria, apesar de previsões legais expressas, ainda se encontra normatizada por diversas misturas de elementos normativos de tipo e normas penais em branco, o que dificulta, e muito, a efetiva fiscalização e repressão dos crimes ambientais e descumprimentos legais. Ressalte-se ainda que, dada a antiguidade da legislação acerca do tema, há multas previstas em MVR (Maior Valor de Referência) (como por exemplo, a penalidade prevista no artigo 17, II, da Lei 7.802/89), índice que se encontra extinto há anos (atualmente o índice utilizado é o INPC), motivo pelo qual as multas passaram a ser arbitradas judicialmente - e ponderadas caso a caso. Disso decorre uma severa dificuldade em se verificar eficácia na aplicação da lei, ante a morosidade e a relativização do efeito erga omnes, que, em tese, deveria ser basilar na legislação.

\section{Conclusão}

A partir do estudo, percebeu-se correlação entre a escolaridade do produtor e o manuseio correto e menos deletério das substâncias pesticidas. As informações sobre tipos de cultura e forma de cultivo apresentaram discrepância em relação a outros autores, anteriormente, visto que alguns produtores expuseram a necessidade de diversificação de culturas para sobrevivência de suas propriedades, tendo em vista a impossibilidade de aquisição de doses crescentes de pesticidas para a cultura do tomate. As embalagens da maioria das propriedades visitadas são descartadas de forma incorreta. De modo geral, sem a devida orientação técnica, não percebem a contaminação do aquífero pelo uso de agrotóxicos e estão sujeitos às patologias crônicas que afetam órgãos vitais e podem bioacumular contaminantes.

Os dados obtidos, predominantemente qualitativos, levantaram a demanda de assistência ao produtor familiar no que tange o uso de agrotóxicos e descarte de embalagens nas cidades de Paty do Alferes e Miguel Pereira, fornecendo embasamento para futuros estudos e pesquisas nas regiões citadas e corroborar com a conscientização sobre os riscos que o uso de agrotóxicos pode acarretar para a biodiversidade de fauna, flora e para a saúde pública.

As limitações do presente trabalho foram ocasionadas pela dificuldade de acesso aos agricultores, no que diz respeito 
à localização geográfica, visto que muitas plantações estavam situadas em propriedades privadas com sinalizações proibitivas à visitação. Ainda relacionada a acessibilidade pode-se aferir como adversidade encontrada a não receptividade de muitos agricultores, principalmente por temerem que a visita se tratava de algum tipo de fiscalização governamental.

Futuras pesquisas baseadas no estudo em questão podem surgir através da avaliação da poluição dos aquíferos das propriedades, do nível de contaminação do solo e da análise da saúde dos agricultores. Gerando assim, uma perspectiva mais recente para monitoramento dos envolvidos na agricultura regional.

Algumas ações práticas em função dos resultados obtidos podem ser recomendadas, como por exemplo a realização de atividades de extensão rural, visando incorporar boas práticas de aplicação dos pesticidas, quando necessário, e enfatizando a utilização de equipamentos de proteção e de um descarte adequado das embalagens de pesticidas como as únicas vias para se preservar a saúde das pessoas e animais na unidade produtora. Visitas periódicas, que objetivem um apoio técnico serão mais eficazes no contexto local do que informações disponíveis em rótulos e mídias impressas nas lojas que vendem pesticidas.

\section{Agradecimentos}

As autoras agradecem pelo financiamento da pesquisa ao CNPq, pela bolsa PIBIC.

\section{Referências}

AEMERJ (2017). Paty do Alferes - Histórico. http://aemerj.org.br/index.php/municipios/80-paty-do-alferes

Barbour, R. (2009). Grupos focais: coleção pesquisa qualitativa: Bookman. 219 p.

Bernhardt, E. S., Rosi, E. J., \& Gessner, M. O. (2017). Synthetic chemicals as agents of global change. Frontiers in Ecology and the Environment, 15(2), 8490. $10.1002 /$ fee. 1450

Bertolino, A. V. F. B. (2004). Monitoramento dos fluxos de água no solo sob diferentes tipos de manejo e uso - Estação experimental de Avelar (Paty do Alferes) [tese]. Universidade Federal do Rio de Janeiro.

Brasil (1989). Lei 7.802, de 11 de julho de 1989. http://www.planalto.gov.br/ccivil_03/LEIS/L7802.htm.

Brasil (1996). IBAMA. Portaria Normativa Ibama nº 84, de 15 de outubro de 1996. Diário Oficial da União, Edição n 203, Seção 1 , Brasília, DF 18 out. 1996. Brasil (1998). Lei 9.605, de 12 de fevereiro de 1998. http://www.planalto.gov.br/ccivil_03/leis/19605.htm.

Brasil, (2002). Decreto n 4.074 , de 04 de janeiro de 2002. http://www.planalto.gov.br/ccivil_03/decreto/2002/d4074.htm.

Brum, B. R., D’ Ávila, R. dos S., Sguarezi, S. B., Santos Filho, M. dos., \& Ignácio, Á. R. A. (2020). Temporal analysis of the use of birds, as environmental sentinels in the monitoring of contamination by pesticides. Research, Society and Development, 9(7), e752974807. https://doi.org/10.33448/rsd-v9i7.4807

Cardoso, D. da S. C., \& Cavalcanti, N. T. (2017). A política de regionalização turística do Vale do Café (RJ) e seus desdobramentos nos municípios: uma abordagem das relações do Poder Público com os Stakeholders. Khóra - Revista Transdisciplinar, Rio de Janeiro, 4(5).

Carvalho, C. R. F., Niraldo, J. P., \& Cláudio, L. M. S. (2016). Levantamento dos agrotóxicos e manejo na cultura do tomateiro no município de Cambuci-RJ. Rio de Janeiro. Ciência Agrícola, Rio Largo, 14(1), 15-28.

Dias, C. A. (2000). Grupo focal: técnica de coleta de dados em pesquisas qualitativas. Informação \& Sociedade: Estudos, 10(2), 1-12. https://periodicos.ufpb.br/ojs/index.php/ies/article/view/330.

Durigon, V. L. (2016). Avaliação da Cobertura e Perdas de Solo na Bacia Hidrográfica Palmares-Ribeirão do Saco, em Paty do Alferes e Miguel Pereira-RJ, Através de Técnicas de Sensoriamento Remoto e SIG [tese]. Seropédica: Universidade Federal Rural do Rio de Janeiro.

EMBRAPA - SNLCS (2000). Serviço Nacional de Levantamento e Conservação de Solos. Levantamento e aptidão agrícola das terras do Córrego da Cachoeira, Paty do Alferes, RJ. Rio de Janeiro. 43 p.

EMBRAPA - SNLCS (2010). Serviço Nacional de Levantamento e Conservação de Solos, Normas gerais sobre o uso de agrotóxicos. Sistemas de Produção, 1 - 2a. edição, ISSN 1807-0027. http://www.cpatsa.embrapa.br:8080/sistema_producao/spuva/agrotoxicos.html\#1.

Faria, N. M. X., Rosa, J. A. R., \& Facchini, L A. (2009) Intoxicações por agrotóxicos entre trabalhadores rurais de fruticultura, Bento Gonçalves, RS. Rev Saúde Pública, 43(2):335-44

Gilson, I. K., Rocha, L. G., Silva, M R. V., Wammes, S. W., Leite, G. dos S., \& Welter, T. (2020). Agrotóxicos liberados nos anos de 2019-2020: Uma discussão sobre a uso e a classificação toxicológica. Braz. J. of Develop., Curitiba, 6(7), 49468-49479.

Gondim, S. M. G. (2003). Grupos focais como técnica de investigação qualitativa: desafios metodológicos. Paidéia, 12(24), Ribeirão Preto - SP, 149-161 
Research, Society and Development, v. 10, n. 5, e32110515045, 2021

(CC BY 4.0) | ISSN 2525-3409 | DOI: http://dx.doi.org/10.33448/rsd-v10i5.15045

IBGE- Instituto Brasileiro de Geografia e Estatística. Censo Agropecuário (2017). Relatório da produção de lavouras temporárias e permanentes. http://seriesestatisticas. ibge.gov.br/lista_tema.aspx?op=0\&no=1.

IBGE- Instituto Brasileiro de Geografia e Estatística. (2019). Portal de mapas do IBGE. www.ibge.gov.br/home/geociencias/cartografia.

Instituto Cidade Viva. (2013). Guia cultural do Vale do Café. Editora Cidade Viva. 1-87.

Jardim, H. L., Fernandes, N. F., \& Souza, A. P. (2017). Perda de solo em parcelas de erosão, sob diferentes culturas e técnicas de manejo e a análise de estratégias de conservação. XVII Simpósio Brasileiro de Geografia Física Aplicada, 4394 - 4405, Campinas - SP.

Juarez, F. (2011). El concepto de salud: Una explicación sobre su unicidad, multiplicidad y los modelos de salud. International Journal of Psychological Research, 4(1), 70-79.

Leopold, A., Roberts M., \& Matthiessen, P. (2017). Ecotoxicological Hazard and Risk Assessment of Endocrine Active Substances. Integrated Environmental Assessment and Management, 13(2), pp. 264-266.

Marco, M. A. (2006). Do modelo biomédico ao modelo biopsicossocial: um projeto de educação permanente. Revista Brasileira de Educação Médica, Rio de Janeiro, 30(1).

Moragas, W. M., \& Schneider, M. D. O. (2003). Biocidas: suas propriedades e seu histórico no Brasil. Caminhos de Geografia, 3(10), p 26-40. UberlândiaMG.

Oliveira, A. A. R., Leite Filho, C. A. P., \& Rodrigues, C. M. C. (2007). O Processo de construção dos grupos focais na pesquisa qualitativa e suas exigências metodológicas. Anais do XXXV Encontro da ANPAD, 22 a 26 de setembro de 2007, 1-15, Rio de Janeiro - RJ.

Oliveira, L., de \& Tooge, R. (2021). Número de agrotóxicos registrados em 2019 é o maior da série histórica; 94,5\% são genéricos, diz governo. Portal G1 de Notícias. $\quad$ https://g1.globo.com/economia/agronegocios/noticia/2019/12/28/numero-de-agrotoxicos-registrados-em-2019-e-o-maior-da-serie-historica945percent-sao-genericos-diz-governo.ghtml.

Santos, V. M. R. dos., Donnici, C. L., DaCosta, J. B. N., \& Caixeiro, J. M. R. (2007). Compostos organofosforados pentavalentes: histórico, métodos sintéticos de preparação e aplicações como inseticidas e agentes antitumorais. Química Nova, 30(1), 159-170. https://doi.org/10.1590/S0100-40422007000100028

Souza, G. P. G. de, Souza, M. F. da C., Galdino, C. V., Balbino, C. M., Silvino, Z. R., \& Joaquim, F. L. (2020). Pesticide use by rural workers in the municipality of Paty do Alferes-RJ/Brazil. Research, Society and Development, 9(7), e846974933. https://doi.org/10.33448/rsd-v9i7.4933

Sousa, J. A., Feitosa, H., Carvalho, C. M., Pereira, C. F., Feitosa, S. O., \& Silva, S. L. (2016) Percepção dos produtores rurais quanto ao uso de agrotóxicos. Revista Brasileira de Agricultura Irrigada. 10(5), 976-89.

Yin, R. K. (2015). O estudo de caso: Bookman. 